Florida International University FIU Digital Commons

6-24-2004

\title{
The impact of migration and intergenerational changes on the Cuban family in the United States
}

Darna Aybar Guardia

Florida International University

DOI: $10.25148 /$ etd.FI14032382

Follow this and additional works at: https://digitalcommons.fiu.edu/etd

Part of the Sociology Commons

\section{Recommended Citation}

Aybar Guardia, Darna, "The impact of migration and intergenerational changes on the Cuban family in the United States" (2004). FIU Electronic Theses and Dissertations. 1351.

https://digitalcommons.fiu.edu/etd/1351 
FLORIDA INTERNATIONAL UNIVERSITY

Miami, Florida

THE IMPACT OF MIGRATION AND INTERGENERATIONAL CHANGES ON THE CUBAN FAMILY IN THE UNITED STATES

A thesis submitted in partial fulfillment of the

requirements for the degree of

MASTERS OF ARTS

in

COMPARATIVE SOCIOLOGY

by

Darna Aybar Guardia

2004 
To: Dean R. Bruce Dunlap

College of Arts and Sciences

This thesis, written by Darna Aybar Guardia, and entitled The impact of Migration and Intergenenerational Changes on the Cuban family in the United States, having been approved in respect to style and intellectual content, is referred to you for judgment.

We have read this thesis and recommend that it be approved.
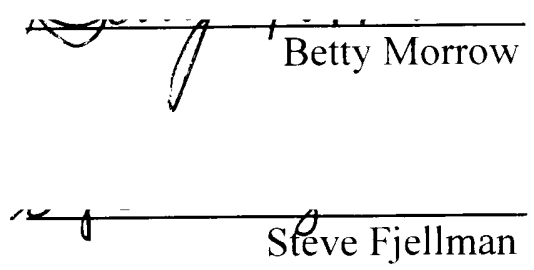

Lisandro Perez, Major Professor

Date of Defense: June 24, 2004

The thesis of Darna Aybar Guardia is approved

Florida International University, 2004 


\section{ABSTRACT OF THE THESIS}

THE IMPACT OF MIGRATION AND INTERGENERATIONAL CHANGES ON THE CUBAN FAMILY IN THE UNITED STATES

by

Darna Aybar Guardia

Florida International University, 2004

Miami, Florida

Professor Lisandro Perez, Major Professor

This study examines changes in the Cuban family in the United States produced by time, migration, and the rise of new generations. The thesis will use a data set extracted from the 5\% Public Use Microdata Series (PUMS) of the U.S. Decennial Census of Population for the years 1970, 1980 and 1990. Contingency table analysis and comparison of means were used to examine various family-related variables.

The analysis points to changes in the traditional Cuban family towards less traditional family arrangements. The multigenerational feature of the Cuban household has diminished as the elderly have become independent and are more likely to be living on their own. Although female labor participation remains high, the occupational patterns of the first generation of Cuban women have diversified and a new trend has emerged for the second generation. The second generation of Cuban women demonstrates a strong inclination for white-collar occupations. Fertility rates remain low. 
In conclusion, the Cuban family in the U.S. has changed influenced by time, migration wave and the exposure to the U.S. norms. This process will continue as new immigrants arrive and new generations mature. 


\section{TABLE OF CONTENTS}

\section{INTRODUCTION}

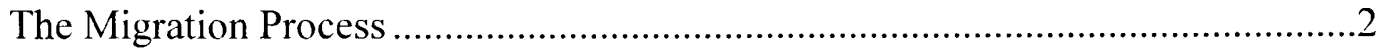

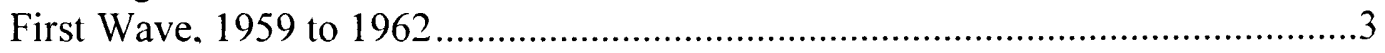

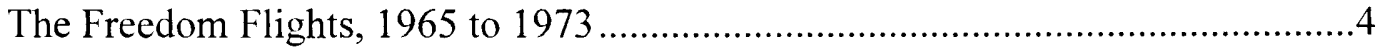

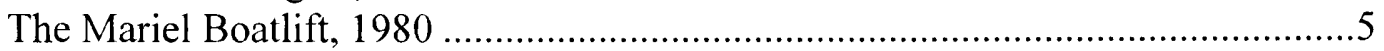

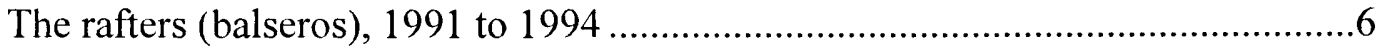

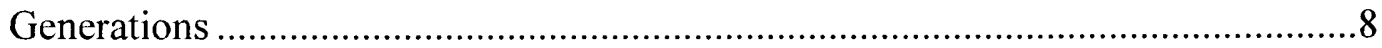

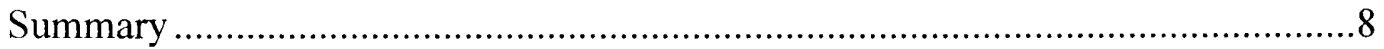

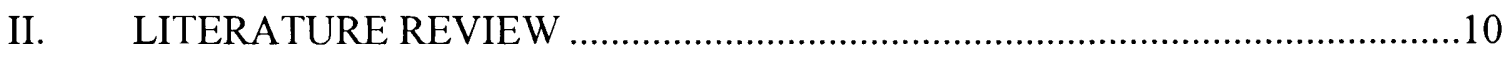

The Migration Process: The importance of the waves.........................................10

Migrant Families ........................................................................................ 13

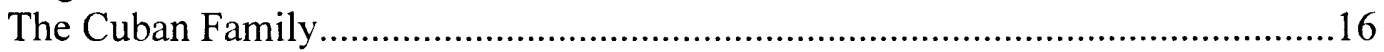

Household Composition.................................................................................18

Female Labor Participation..........................................................................19

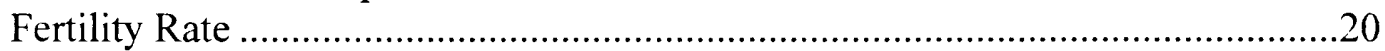

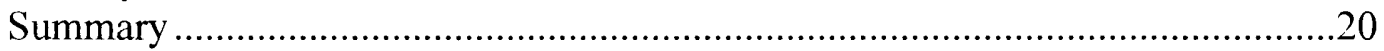

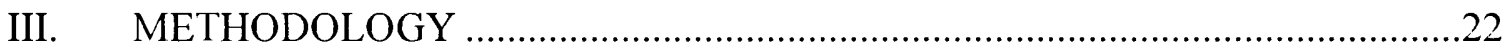

IV. TRENDS IN THE EVOLUTION OF THE CUBAN FAMILY ..........................24

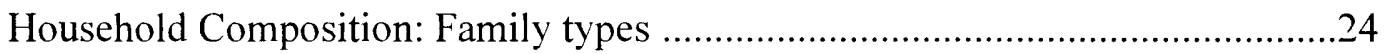

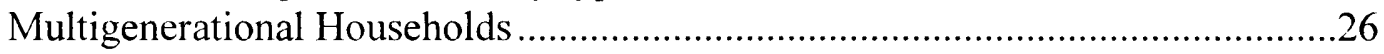

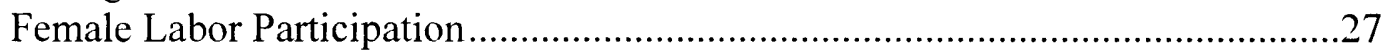

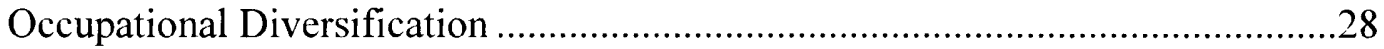

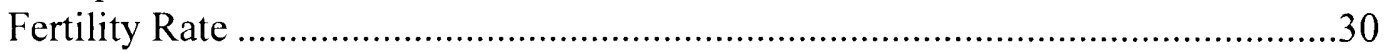

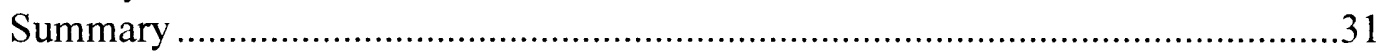

V. DIFFERENCES AMONG THE WAVES AND

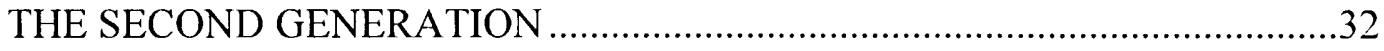

Household Composition: Family Types ……………........................................32

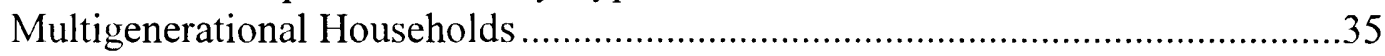

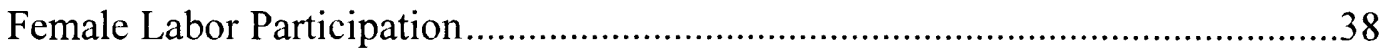

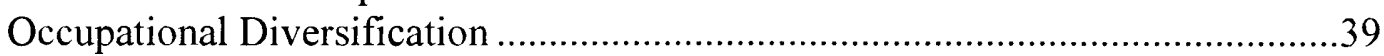

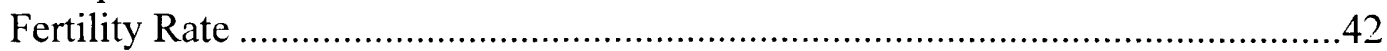

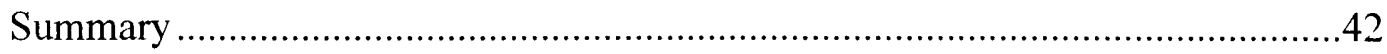


VI. DISCUSSION 


\section{LIST OF FIGURES}

1. Occupational patterns for Cuban women, 1970 to 1990

2. Percent distribution of the Cuban origin population

living in married couple families by wave of arrival.

3. Percent distribution of the Cuban origin population

living in female headed households by wave of arrival.

4. Percent distribution of the Cuban origin population

living in other family types by wave of arrival.

5. Percent distribution of the Cuban origin population over 65 who are heads of households or the spouse of the head of household by wave of arrival

6. Percent of the Cuban origin population who are parents/

parents in law of the head of household by wave of arrival

7. Cuban women by labor force status and wave of arrival

8. Percent distribution of Cuban women by occupation and wave of arrival.

9. Percent distribution of Cuban women by occupation and generation 


\section{Introduction}

Forty-five years have passed since the start of the social revolution that changed the lives of all Cubans regardless of their political ideology or social position. It was a social revolution that produced conflict and change and altered the way most Cubans conducted their everyday lives. It also transformed the most fundamental social institutions, including the family. According to Smith and Padula in their study of the Cuban family in the 1980s: "The revolution believed in essence that the traditional family was too influential and individualistic for the state to be able to achieve its vision of economic development and social justice"(Smith and Padula, 1990, p.175)

The revolution triggered a process of migration that continues to this day. Cubans have taken advantage of legal and illegal opportunities to abandon the island, taking entire families at times, or even separating families in the hope of reuniting in the future outside the country. The Cuban migration story has been..."a surreal and incredulous drama with one major theme: the drastic and irreversible impact of political forces on individual human lives"(Grenier and Perez, 2003, p.21). The social revolution of 1959 threatened the stability of Cuba's social institutions, producing an atypical migration to the U.S. Although young unmarried men usually predominate among international migrants, Cuban migration to the U.S has included a disproportionately high number of elderly persons and females (Perez, 1986, p.126). As we shall see, the unusual political context of the migration accounts for this anomaly.

The hostile nature of the relations between the U.S and Cuban governments has had an impact on the migration process, resulting in several distinct arrival waves. These waves have differed a great deal from each other in their specific origins, conditions, and 
characteristics (Perez, 1986). "The timing, length, intensity, and characteristics of each wave are largely consequences of the conditions under which the migration wave from Cuba to the United States is allowed to take place." (Perez, 2001, p.93). Compared to the flow from a water faucet, Cuban migration has been turned on and off by the Cuban and U.S. governments according to their political agendas (Perez, 2001, p.91)

Through the arrival of successive migration waves, the Cuban population has grown increasingly heterogeneous. With the passing of time, the rise of new U.S born generations have also increased the diversity of the Cuban population in the U.S

This thesis proposes to examine the changes that have taken place in the traditional patterns of family organization of Cuban immigrants, examining those changes across migration waves and generations.

\section{The Migration Process}

The Cuban revolution produced social, political, religious and economic changes for most Cubans. Cubans reacted in different ways to the new government policies; they supported some changes while resenting others. The pervasive and radical nature of the changes induced many people to migrate (Garcia, 1996).

Cuban migration became an intermittent process manipulated by the hostile relations between the Cuban and U.S. governments. The waves are temporal categories with contrasting demographics. Nevertheless, each wave has been characterized as a group, and examined relative to the island's population (Ackerman and Clark, 1995). According to Grenier and Perez (2003), although these waves have differed a great deal from each other in their specific conditions and characteristics, they all have been the result of an international conflict that has utilized migration as a political tool (p.22) 


\section{First wave, 1959 to 1962}

The migration process has been viewed as a class phenomenon, involving a successive peeling-off, starting at the top, of the layers of the pre-Revolutionary class structure (Perez, 1986, p.129). From January 1959 to October 1962 approximately 248, 070 Cubans emigrated to the U.S (Garcia, 1996, p.13). The first people to leave were associated with the Batista government. Many had placed their money in foreign banks making their migration process easier than for those who followed. The migration followed a logical socioeconomic progression. Cubans of the upper classes were the first to leave, followed by the middle class. These Cubans emigrated in response to the increasing radicalization of the Cuban government. As refugees from communism during the height of the Cold War, they received the sympathy and admiration of most Americans. Because of the U.S. influence in Cuban culture before 1959, this country was the logical choice for the upper and middle classes. The U.S was also the only nation to have an open immigration policy towards the Cubans (Garcia, 1996, p.15).

Many of the early exiles left the island under the assumption that their departure was temporary. They perceived themselves as political exiles, not immigrants (Garcia, 1996, p.15). The U.S. government shared the perception of Cubans as temporary visitors, granting them parole status. Cubans' parole status permitted them to seek employment in the U.S., a right generally granted only to those with permanent residency (Garcia 1996, Perez, 1986). Cuban refugees were also the first to receive government- surplus food. Only later did state and local agencies extend this service to needy Americans (Garcia, 1996, p.29) 
Family was at the core of the Cuban migration process. Many parents sent their children ahead fearing political indoctrination; others sought to protect boys from military service. Consequently, many children arrived in the U.S unaccompanied. More than half were between the ages of thirteen and seventeen, and over two thirds were boys.

It has been estimated that among Cubans arriving in this country from 1960 to 1962 , up to 37 percent of household heads were proprietors, managers, or professionals. Among the 1960-62 Cuban immigrants, 12.5 percent had completed four or more years of college (Garcia, 1996, Perez, 1986)

Flights out of Cuba continued until October 1962, when the U.S confronted the Soviet Union over the presence of nuclear missiles in Cuba. The Missile Crisis ended the first major wave of Cuban immigrants.

\section{The Freedom Flights, 1965 to 1973}

In September of 1965, Fidel Castro announced that all Cubans with relatives in the U.S who wished to leave could do so. He opened the port of Camarioca in Matanzas province as the port of departure. By November of 1965, 2,866 people had abandoned the island through this port. President Johnson's administration announced that it was willing to accept more Cubans through an airlift. He also stated that priority would be given to the parents, children, and spouses of Cubans already living in the U.S and to political prisoners. Beginning December $1^{\mathrm{st}}$, chartered planes traveled to Varadero, twice a day, transporting between three and four thousand people each month to Miami (Garcia, 1996).

The second wave of Cuban immigrants was different from the first in several ways: 1) the U.S and Cuba controlled the migration, choosing who would leave. 2) Cubans in this 
wave were socio-economically different: only 12 percent of this second wave were professionals or managers and 57 percent were blue collar, service, or agricultural workers; 3 ) women and the elderly were over represented during this wave and males of military age were excluded. By the end of the freedom flights, the Cuban community had become more heterogeneous. Cubans of every social class and profession were represented, as were various ethnic groups (Garcia 1996, Grenier and Perez, 2003).

\section{The Mariel boatlift, 1980}

Although by 1973 both governments agreed to terminate the airlift, migration from Cuba continued. Several thousands came to the U.S through third countries, while others abandoned the island clandestinely.

Popular discontent threatened the stability of the Cuban regime, and emigration once again provided a safety valve for Cuban society. In April 1980 six people broke into the Peruvian embassy in Havana in response to the Cuban government withdrawal of the guards at the embassy. Shortly thereafter, about 10,000 persons crowded into the building and its grounds hoping to leave the island (Grenier and Perez, 2003). The Peruvian and Cuban governments negotiated an emigration that required the collaboration of several countries and the airlift began on April 16. Castro suspended the flights four days after they began (Garcia, 1996, p.58).

As he had done in 1965, Castro announced that all who desired to leave could do so. Cubans in the U.S took the opportunity to reunite with their families. Thousands of émigrés sailed across the Florida Strait in yachts, sailboats, shrimpers, and even freighters to pick up their relatives. Between April to October 1980, 125776 Cubans arrived in the U.S, comprising the third wave of Cuban migration. 
The Cubans from this third wave were different from the early exiles. It included, for the first time, sizable representation from Cuba's lower socioeconomic sectors and its nonwhite population (Perez, 2001, p.94). In addition, Castro took this opportunity to rid the island of criminals: 26,000 refugees had criminal records (Garcia, 1996, p.64). A number of the refugees had either physical or mental disabilities. An estimated fifteen hundred had mental health problems or were mentally retarded of which five hundred were judged to need long- term institutionalization. Another five hundred were eventually placed in halfway houses (Garcia, 1996).

The Mariel Cubans arrived at a time when Americans were less sympathetic to the plight of immigrants. They arrived during an economic recession, high unemployment and high interest rates. Most Americans viewed them as burdens on the national economy. The reaction of the Cuban-American community was not much different. Initially Cuban Americans pooled their resources to assist the new refugees, but as the news of the criminal records of some of the refugees were made public, the early exiles took great care to distinguish themselves from the "Marielitos". The Cuban community feared that these "new Cubans" would never fit in their society (Garcia, 1996). Unlike the earlier waves, these new migrants encountered hostility and discrimination wherever they settled. Neither their homeland nor their host society wanted them (Garcia, 1996).

\section{The rafters (balseros), 1991-1994}

A balsero (rafter) is any person who exits Cuba illegally, by sea, in a small boat or homemade craft. The balsero (rafter) phenomenon can be conceptualized as an illegal, post-revolutionary form of exit that has gone through two temporal cycles: the early cycle (1959-1973) and the latest cycle (1983-1994). During the period 1991-1994, the U.S 
Coast Guard rescued 45,575 balseros (Ackerman and Clark, 1995). It was during this period, especially 1994, that the exodus of balseros was most intense. It was the beginning of the "Rafter Crisis."

After the collapse of Eastern Europe, the Cuban economy that depended on the Soviet subsidies, suffered greatly. The situation for most Cubans became intolerable. This, in addition to the development of a dissident movement inside the island and the tightening of the embargo threatened once more to destabilize the system. As in the past, Castro used migration as a strategy to stabilize the situation. After street riots took place on August $5^{\text {th }} 1994$ in the streets of Havana, Castro instructed the Cuban Coast Guard not to discourage migration (Perez, 1996). Cubans began to leave the island in massive numbers. Hoping to reach the U.S., these new refugees left on "balsas" (rafts), tires, or other makeshift vessels, risking death from starvation, dehydration, drowning, or sharks (Perez, 1996).

In a sudden policy change by the Clinton administration, most of the new refugees were not allowed to reach American soil. They were sent instead to the U.S naval base in Guantanamo, Cuba.

Ackerman and Clark (1995) divide the rafters into two groups, those who entered the U.S directly and those who went to Guantanamo. According to Ackerman and Clark, those who entered the U.S directly between 1991 and 1994 were the youngest group of Cuban refugees yet, with a median age of 27 . There were relatively few females (26.9 percent) and most men were married (65.2 percent). There was an increase in the percentage of women and children between 1991 and 1994. In 1991 women made 20 percent but by 1994 they accounted for 36 percent. In the case of children, in 1991 they 
amounted to 11 percent but by 1994 they made up 14.4 percent. According to Ackerman and Clark, as the phenomenon grew, more entire families took the risks. In the Guantanamo group, 16.5 percent were women, 83.5 percent were males and 36 percent were single. As in the Mariel boatlift young males were over represented.

\section{Generations}

By $1990,31.6$ percent of the Cuban origin population in the U.S was born in this country. The second generation differs in many ways from the first. Exile, for the second generation, is an inherited circumstance, not a profound loss (Pedraza, 1996). The first generation experienced a social revolution and was forced to leave their homeland. They adapted their customs and traditions to the realities of the new society. Many faced, at least during the first years, downward mobility. Many left behind property and successful careers and built new ones in the U.S. The first generation eventually established an economic enclave that would foster upward mobility and economic success.

For the second generation, the U.S has always been home. Cubans of the second generation are bilingual, and English is the language of choice (Garcia, 1996). They have been raised under U.S. institutions and socialized in American schools (Pedraza, 1996). This generation is expected to be different from the first; they have been influenced by U.S. culture and by their parents' specific circumstances, including the wave in which they arrived.

\section{Summary}

The social revolution of 1959 changed the way most Cubans lived. It produced a migration process that continues to this day. This migration has not been constant. The 
hostile relations between Cuba and the U.S have largely shaped it. Every decade since 1959 has witnessed a distinctive wave of Cuban immigrants, so the Cuban population in the U.S has become heterogeneous.

The first generation established cultural patterns and a socio-economic enclave that foster the economic adjustment of Cubans in the U.S. The second generation has been influenced by their parents' circumstances but they have largely been shaped by the culture of the host society, so they in many ways differ from their parents.

The Cuban-American family is a representation of the Cuban population in the U.S. It has evolved through time and generations. It has been influenced by migration and by exposure to American culture. This thesis will examine how the family has evolved within that shifting context. 


\section{Chapter 2}

\section{Review of the Literature}

This thesis will bring together two distinct bodies of literature on Cubans in the U.S. One is the literature on the migration process, especially the impact of different waves, their distinctiveness, and the changing contexts of reception in the U.S (Ackerman 1995, Garcia 1996, Grenier 2003, Pedraza 1996, Perez 1986b). This body of work emphasizes the high human capital of the first wave and the enclave it created, an enclave that conditioned the economic adjustment of the later waves and also of the second generation. (Perez-Firmat 1994, Perez 1986, 2001, Rumbaut 2001)

The second body of literature deals with the Cuban-American family, with its almost exclusive emphasis on the distinctive characteristics of the first wave: the multigenerational household, high female labor force participation, and low fertility (Aguirre 1981, Ferree 1979, La Liberte 1976, Perez 1986, Rumbaut 1976, Szapocznik 1978,1988 ). This project will wed those two areas by examining the impact of the migration process and generational changes on the family.

\section{The migration process: The importance of the waves}

The Cuban migration process, as we have seen, has not been steady. As Perez explains, it has been more akin to the flow from a water faucet: abruptly turned off and on at the will of those in power in Havana and Washington according to political considerations (Perez, 2001, p.92). Very distinctive waves or refugee "vintages" have divided this process (Pedraza, 1996, p.263). These migration waves have been very important in the evolution of the Cuban-American population of the U.S and the establishment of a socio-economic enclave. 
The distinctiveness of each migration wave shaped the Cuban population in the U.S. Not only have the waves been different demographically, the experience of the émigrés varied from wave to wave and so did their reception to the U.S. Due to the uniqueness of each wave and the differences in the reception of the host society, the Cuban population in the U.S became increasingly heterogeneous. As stated by Lisandro Perez, "there are Cubans and there are Cubans" (Perez, 2001, p.97).

Perceptions about each wave of immigrants have been formed in response to the specific conditions in which they abandoned the island and the context in which they were received. During the last forty five years, the distinctiveness of the Cuban migration has fed the debate over its meaning. On the one end the immigrants have been seen as political refugees and on the other as economic immigrants. In reality, they are both. As Pedraza explains, all societies are simultaneously and inextricably political and economic. Political and economic conditions are intertwined. In a society in transition, political disaffection easily results when government policies to change the basic economic system dislocate people as they lose their economic, social and ideological place (Pedraza, 1996, p.277). The Cuban and U.S governments have regulated the Cuban migration process (Garcia 1996, Grenier and Perez, 2003, Perez 2001), and have also defined the immigrants as political or economic. For many years, Cubans were recognized and welcomed as political immigrants. This however, has changed. During the last crisis, 1994-1995. Cubans became aliens attempting to enter the U.S illegally. With the end of the Cold War and under the resurgence of nativistic attitudes across the land, Cubans have now become undocumented refugees (Pedraza, 1996, p.277) 
Cuban migrants entering during the 60's did not perceive themselves as immigrants; they saw themselves as exiles. The U.S government did not perceive them as immigrants either. An immigrant has been pulled by the attraction of the opportunity of a better life. A political exile has left in fear for his safety given his interpretation of events and selfperceived danger (Pedraza, 1996, p.264). The first wave of Cuban immigrants left the island in fear. They represented the elite of Cuban society and they have therefore been the principal standard-bearers in the sustained struggle against the Cuban government, the faithful keepers of the exile legacy (Grenier and Perez, 2003, p.23).

Amaro and Portes (1972) argue that, over time the political exile increasingly became an economic exile (Pedraza, 1996, p.267). During the second wave, the Airlift, the perception began to change. Cubans of the second wave were perceived as immigrants. Immigrants are distinctive because they have experienced another life in another country, another culture, yet they will live out a whole new set of choices and experiences, depending on their age and circumstances in the new society (Pedraza, 1996, p 11). These new immigrants began to contribute to the diversity of the Cuban population in the U.S by introducing an atypical immigrant population in which women and the elderly were over represented.

In 1980, during the Mariel boatlift, the perception about this third wave of Cuban immigrants changed dramatically, not only for mainstream U.S but also for the established Cuban-American community. As Maria Cristina Garcia explains, between the Mariel Cubans and those who had emigrated in the early days of the revolution lay twenty years of social and ideological differences, and the older émigrés worried that the Mariel generation, raised under a socialist and authoritarian regime, would never adapt to 
democratic institutions and free enterprise (Garcia, 1996, p.72). The Mariel refugees, by including for the first time the lower sectors of the Cuban society and its non-white population, change the image and self-perception of the Cuban population in the U.S. Cubans in this wave were not defined as exiles or immigrants. These were refugees. A refugee has been pushed out. Given the choice, refugees would stay in their countries (Pedraza, 2003, p.264).

Maria Cristina Garcia emphasizes that to portray Cubans in the U.S by figures that describe them as a whole masks the vastly different social realities that they represent. Those many social realities, according to Garcia, are the result of their manifold migrations (Pedraza, 1996, p.263)).

The various waves of Cuban migration were influenced by the changing phases of the Cuban revolution. Each wave brought very different sets of social resources to a social context that differed from wave to wave. Each wave experienced a different process of incorporation into American society. As Garcia (1996) explains, typically, immigrants experience a pronounced generation gap when parents raised in the old world confront their children raised in the new. In the Cuban case this gap reflects the difference between political generations that result from sharing a common location in a historical social process that subjected them to specific experiences that shape a frame of reference for the future (Pedraza, 1996, p.269).

\section{Migrant families}

A review of the literature on migration demonstrates the important role sociologists attribute to families and households in the migration process. The studies tend to concentrate on the changes in cultural patterns of migrating families and they also 
recognize the need to explore systematically and in depth the adaptation patterns and trajectories of specific ethnic groups (Rumbaut and Portes, 2001, p.11).

Economists have viewed migration as a self- regulating mechanism to restore equilibrium between sending areas, which temporarily possess an excess of labor relative to demand, and receiving areas, where capital resources exceed human resources. A different approach to migration disputes the assumptions that individuals emigrate only in response to imbalances in international wave rates. These researchers argue the household is the true decision maker (Pessar, 1999, p.57). As Patricia R. Pessar explains, while macrostructural transformations unleash migration pressures, it is families and social networks that respond to these pressures and determine which members of households and communities actually emigrate (Pessar, 1999, p.55).

According to Ruben Rumbaut, immigrants and their children in the U.S are rooted in often-complicated webs of family ties both in the sending and receiving countries. Such ties form extraordinary linkages and networks that can, by reducing the cost and risks of migration, expand and serve as an instrument to additional and self- perpetuating migration (Rumbaut, 1999, p.189). In other words, migration produces a cycle of events: life for migrant families change, they increase their levels of consumption and production and, in turn, these changes have an effect on the nonimmigrant families that begin to view migration as an alternative.

Studies on migrant families also recognize that the cultures of immigrant groups differ both from the culture they left behind in the sending country and from the U.S mainstream (Foner, 1999, p.260). Immigrants do not exactly reproduce their old cultural patterns when they move to a new land, but these patterns continue to have a powerful 
influence in shaping family values and norms as well as actual patterns of behavior that develop in the new setting. Old cultural patterns are influenced by new conditions in the receiving society. As Nancy Foner explains, external forces in the new environment also shape immigrant family lives as they provide new opportunities and constrains as well as new sets of values, beliefs, and standards (Foner, 1999, p.262). Immigrants are inevitably influenced by the American cultural beliefs and values concerning marriage, family, and kinship that are disseminated by the mass media, schools and other institutions. In addition, U.S immigration law is also recognized as a significant agent. It defines who is a member of the family according to U.S law, facilitating the immigration of some family members (parents, legitimate children, and legal spouses) while often separating illegitimate children and common law spouses (Foner, 1999, p.263).

Research on migrant families points to the importance of looking at different generations of immigrants. The first generation fuses together the old and the new to create a new kind of family life, while the second generation represents the future of the group. Leif Jensen estimates the number of native-born children of immigrants under age 18 who have one or more foreign-born parent at 11.5 million. It is anticipated that as the predominately white baby- boom generation reaches retirement age, it will depend increasingly for its economic support on the productivity, health, and civic participation of adults who grew up in minority immigrant families (Jensen, 2001. p.22).

The migrant family is not only the designer of economic strategies for survival but it is also the builder of a new culture in the context of a new environment. Immigrants are not passive individuals who are acted upon by external forces. They play an active role in reconstructing and redefining family life (Foner, 1999). Cultural patterns, beliefs and 
values not only change as a result, but they also change in function of the new environment

\section{The Cuban family}

Family has been, historically, one the most significant institutions for Cubans. Prior to independence from Spain in 1898 and, most assuredly, throughout the prerevolutionary era, the average Cuban's sense of national identity, security, and emotional stability were established primarily through the family system and other patterns of intrafamily relationships (Szapoznic and Hernandez, 1988, p.165). Social mobility for the individual largely depended on the family network's social, political, and economic resources, which were enhanced by an elaborate ideology of family honor (Aguirre, 1981). According to Szapoznic and Hernandez (1988), Cubans had a strong preference for linear or hierarchical family relations and thus, traditionally at least, parents expected absolute obedience from their children, and husbands expected the same from their wives.

For Cubans in the U.S, family is at the core of the dense social networks within the enclave and is a crucial resource in implementing upward mobility, reinforcing the culture of the home country, and promoting community solidarity (Grenier and Perez, 2003, p.55). The profile of the Cuban population in the U.S changed with each migration wave and so did the Cuban family.

The Cuban family demonstrated great ability to retain cultural patterns, while adapting to a totally different social system. According to Szapoznic and Hernandez (1988), the younger families of the 1980's were usually comprised of spouses that grew up in the U.S and thus were less likely to find disruptive a greater equality in decision making. In his 
study of the marital stability of Cubans in the United States, Aguirre (1981) used a model that took into consideration the effects of migration on the stability of marriage. This model assumed that marital stability increases with: 1) nearness of residence to the culture of origin, 2) nearness of the family to other kin, 3) lesser amounts of assimilation of foreign culture by the family members, 4 ) greater amount of instrumental ability of the husbands, and 5) greater fertility of the married pair. The results of this study contradicted its original predictions. It showed that Cuban marriages in the United States were quite modern but still stable. Aguirre concluded with the assumption that this stability could be based on democratic companionship procedures (p.387).

The Cuban family evolved, influenced by time, migration and exposure to the U.S culture. The changes across time and generations are significant and have tended to be overlooked in the literature.

As previously explained the social revolution of 1959 threatened the stability of the Cuban socio-economic system, producing an atypical migration to the U.S. Contrary to the typical immigrant profile, which is usually composed by young unmarried men traveling without a family, in the Cuban case, there have been two demographic characteristics not usually found in groups of recent immigrants: a high proportion of elderly persons; and a numerical predominance of females (Grenier and Perez 2003, Perez 1986).

The literature on the Cuban-American family emphasizes the distinctive characteristics of the typical family from the first migration wave. The first two waves, the early exiles 1959-1962, and the Airlift, 1965-1973, established in the U. S distinctive patterns of family organization: multigenerational households, high female labor force 
participation, and low fertility (Perez 1986, Perez 1986a, Pedraza and Rumbaut 1996,

Grenier and Perez 2003). This analysis fails to account for the impact of time, differences among migration waves, and the new generations.

The exposure to the U.S. society produced generational changes. Children forced many accommodations. The older generations may have been concerned with the proper ways of retaining 'cubanidad', but their children did not always share their ideological passion (Garcia, 1996). The children of the first generation, adapted to the new culture faster than their parents and grandparents. They became bicultural and bilingual and learned to interact effectively and negotiate with their Anglo-American context (Marina, 1978).

\section{Household composition}

According to the literature on Cubans, in the 1980's the most salient household characteristic of the Cuban population in the U.S was the three-generation family. Older Cubans were not likely to establish households on their own or to be placed in institutions, such as nursing homes (Perez, 1986a).

Work on the early waves indicated that the traditional Cuban family had begun to change before 1959 (Szapocznic and Hernandez, 1988). Cubans traditionally preferred an extended, much involved, inclusive family style. The nuclear family was tightly knit, but it allowed for the inclusion of other relatives, including godparents, within the household (Marina, 1978). In the U.S. the Cuban family became more nuclear. The multigenerational feature of the early waves changed. During the first two decades of exile, the elderly were very vulnerable and dependent on the household unit (Grenier and Perez, 2003). Their income and caretaker services were crucial for the economic stability 
of the family (Perez 1986, Grenier and Perez 2003). The 1980 U.S census revealed that one fourth of the Cuban born persons over 65 lived in household in which they were parents or parents in law of the householder (Grenier and Perez, 2003).

\section{Female Labor Participation}

Before the 1959 revolution, it was not common for Cuban women to work outside the home. Women constituted only about 13 percent of the labor force. Working outside the home was considered a sign of independence from male authority (Ferree, 1979). In the U.S, on the contrary, high female labor participation has been at the core of the Cuban economic success story. Cuban women were more likely to work and they were more likely to work full time (Perez, 1986). In many cases they were the first to be employed because employers paid them even lower salaries than men (Garcia, 1996). Census data indicated that in 1979 the percent of all Cuban women 16 and over in the labor force was 55.4 compared to 49.3 percent of women of Spanish origin and 49.9 percent of U.S women (Perez 1986, p.12).

In the changed economic circumstances in which Cuban families found themselves, women's employment was defined not only as respectable but also as an obligation to their families, but this high labor force participation was not accompanied by changes in other sex role attitudes or by a more equalitarian division of labor at home. According to Ferree:" Cuban women were an example of employment without liberation" (p.35).

Nevertheless, Cuban women became early contributors to the family's economical success (Ferree 1979, Perez 1986, Szapocznic and Hernandez 1988).

Cuban women from the first migration waves settled into blue- collar jobs without aspirations for career advancement. These unskilled or semiskilled jobs did not require 
command of the English language. The most common occupation for Cuban women from the early migration waves was non-durable manufacturing. They found employment in service positions and the garment industry (Grenier and Perez 2003, Garcia 1996). The support of the extended family and the economic enclave were instrumental for the high female labor participation of the early waves (Grenier and Perez, 2003).

\section{Fertility Rate}

The fertility rate has been consistently low among Cubans in the U.S. Having few children had a positive impact of family economic stability and upward mobility. This trend was established by the first waves of Cuban immigrants who were drawn from the most modernized sectors of the pre-revolution society and who had high expectations of upward mobility. This feature of the Cuban family was instrumental for the high rates of female labor force participation and therefore also instrumental in the economic adjustment of Cubans in the U.S. (Grenier and Perez, 2003).

\section{Summary}

The Cuban family in the U.S has evolved. These changes have been a consequence of time, migration, and exposure to American culture. The distinctiveness of the migration waves contributed to the diversity of the Cuban population in the U.S. The Cuban family in the U.S is a reflection of the Cuban population. In other words, just as there are Cubans and there are Cubans, there are Cuban families and there are Cuban families.

Studies on the Cuban family have focused on the typical family of the early waves and have failed to account for these changes. It is necessary now to understand how 
migration, time, and exposure to U.S. society have contributed to the evolution of the Cuban family in the U.S. 


\section{Chapter 3}

\section{Methodology}

The thesis will use a data set extracted from the 5\% Public Use Microdata Series (PUMS) of the U.S. Decennial Census of Population. These are files of 1 percent or more of the total population reporting the responses of individuals to all the census questions on the long form questionnaire. The extractions are from the 1970, 1980, and 1990 census and the selection criteria were all those persons who in those censuses identified themselves as either of Cuban birth, Cuban origin, or Cuban ancestry. The 1979 PUMS file has 5694 records, the 1980 file has 45, 166 records and the 1990 file has 56, 403 records.

The data analysis for this research was conducted using the computer software package SPSS Windows. Contingency table analysis and comparison of means was used to examine three variables: household composition, female labor force participation, and fertility rate. Particular emphasis is placed on comparisons across migration waves and generations.

The variables are operationalized in the data as follows:

1. 1970:

Household composition: Household type, basic relationship, detailed relationship of persons in households. Household type for persons 65 and over. Basic relationship of persons 65 and over. Detailed relationships of persons in household 65 and over. 
Female labor participation: Employment status. Major occupational groups.

Fertility rate: Children ever born to women between 15 and 44 years of age.

2. 1980:

Household composition: Household type. Relationship. Detailed relationship (other relative). Household type for individuals 65 and over. Relationship for individuals 65 and over. Detailed relationship for individuals 65 and over. Female labor participation: Labor force status. Major occupational groups. Fertility rate: Children ever born to women between 15 and 44 years of age.

3. 1990:

Household composition: Household type: Household/ family type. Relationship. Detailed relationship (other relative). Household/ family type for individuals 65 and over. Relationship for individuals 65 and over. Detailed relationship (other relative) for individuals 65 and over.

Female labor participation: Employment status. Major occupational groups. Fertility rate: Children ever born to women between 15 and 44 years of age. 


\section{Chapter 4}

\section{Trends in the evolution of the Cuban family}

The purpose of this chapter is to trace the trends in the evolution of the Cuban family in the U.S; examining those characteristics that have been instrumental in their economic adaptation and focusing on the changes in the traditional patterns associated with the first two migration waves. Household composition, multigenerational households, high levels of female labor participation and low fertility rate have been identified as crucial variables in the study of the Cuban family in the U.S. As we shall see, these family characteristics have been influenced by the distinctiveness of the migration waves, the rise of a new generation of Cuban Americans, and the exposure to norms and values in U.S. society. In this study, I only consider changes in three of the mayor waves, the Exiles, the Airlift, and the Mariel populations. Because the rafters (balseros) are still a very recent population, they are not included.

\section{Family types}

The Cuban family in the U.S has been described as a traditional, patriarchal institution with high levels of dependency and obedience to the male figure (Szapocznik \& Hernandez, 1988). Other studies that took into consideration the effects of migration on the marital stability of Cubans concluded that Cuban marriages in the U.S were modern but stable, and their stability was based on democratic companionship procedures (Aguirre 1981, p.387).

The figures in Table 1 indicate changes from 1970 to 1990 among Cubans in the U.S. Relatively high numbers of Cubans still live in married couple families, with or without 
children. However, large numbers live in families that are not the traditional married couple type associated with the first two waves of immigrants.

\section{Table 1}

Cuban origin population in the U.S, by household type, 1970-1990

\begin{tabular}{rrrrrrr}
\hline & $\mathbf{1 9 7 0}$ & \multicolumn{1}{c}{$\mathbf{1 9 8 0}$} & & \multicolumn{2}{c}{1990} \\
\hline & Number & Percent & Number & Percent & Number & Percent \\
\hline $\begin{array}{r}\text { Total } \\
\text { Married } \\
\text { couple } \\
\text { family }\end{array}$ & 569400 & 100.0 & 903320 & 100.0 & 1171395 & 100.0 \\
$\begin{array}{r}\text { Family with } \\
\text { female head }\end{array}$ & 49500 & 8.7 & 99740 & 11.1 & 160171 & 13.9 \\
$\begin{array}{r}\text { Other } \\
\text { family with } \\
\text { male head }\end{array}$ & 16500 & 2.9 & 28420 & 3.1 & 49657 & 4.2 \\
$\begin{array}{r}\text { Other } \\
\text { family type }\end{array}$ & 28600 & 5.1 & 86760 & 8.7 & 152998 & 11.3 \\
\hline
\end{tabular}

The percent of individuals living in married couple households has decreased from 1970 to 1990 , while the percent of individuals living in female-headed households and the percent of individuals living in other households types, which include persons living alone and in non-family households, has also increased. The percent of individuals living in households with a male head of household without a wife remained consistently low since 1970. This trend towards less traditional households types may reflect the adaptation process to a new society. At least in part it can also be attributed to the aging of the population, the arrival of new waves and the rise of new generations. 


\section{Multigenerational households}

The multigenerational feature of the Cuban family in the U.S has been considered its most salient characteristic. It was considered a product of the group's norms and values. Keeping the elderly home was not only a tradition in Cuban families, but also a duty. It was expected of children to provide and care for their parents in their old age. Cuban elderly were more likely to live with their children than other Hispanic groups. They were also less likely in institutions. 1t has been a very functional arrangement. The elderly contributed to the family economically, including providing caregiver services (Perez, 1986, p.14). The contribution of the elderly to the family's socioeconomic advance and mobility is regarded as a factor in the socioeconomic success of Cubans in the U.S.

The figures in Table 2 indicate that the multigenerational Cuban household has changed. The elderly are now more likely to be living on their own and not with relatives.

Table 2

Number and percent of people over 65 by household relation

\begin{tabular}{|c|c|c|c|c|c|c|}
\hline & 1970 & & 1980 & & 1990 & \\
\hline & Number & Percent & Number & Percent & Number & Percent \\
\hline Total & 35600 & 100.0 & 100680 & 100.0 & 171426 & 100.0 \\
\hline $\begin{array}{r}\text { Head of } \\
\text { household }\end{array}$ & 13500 & 37.9 & 48100 & 47.8 & 90249 & 52.6 \\
\hline Spouse & 4000 & 11.2 & 17100 & 17.0 & 33144 & 19.3 \\
\hline $\begin{array}{r}\text { Other } \\
\text { relative/other } \\
\text { not related to } \\
\text { head }\end{array}$ & 18100 & 50.8 & 35480 & 35.2 & 48033 & 28.0 \\
\hline
\end{tabular}


The percent of individuals 65 and over that are head of household or spouse of the head of household increased substantially, especially between 1970 and 1980, while the percent of seniors living with other relatives or with non-relatives decreased.

Consistent with the previously observed decrease in the number of married couple households and increase in the number of heads of household over 65 , census data indicate that the presence of parents and parents in law of head of household has also decreased among Cubans. In 1970, parents/parents in law of head of household comprise 4.8 percent of the sample. In 1980 , this figure decreased to 3.7 percent, by 1990 parents/ parents in law of head of household only made 2.5 percent.

\section{Female Labor Participation}

High rates of labor participation and employment among Cuban women have been emphasized in the literature on the Cuban family. It has been argued that these family characteristics coexisted with traditional values. For Cuban women in the U.S employment was considered a duty, a way to contribute to the family's well being, and not a sign of liberation (Ferree, 1979). Women's contribution to the family's income has also been a factor in the success story.

Data from the 1970, 1980 and 1990 U.S census indicates that female labor participation among Cubans has remained very high across time. In 1970, 49.7 percent of Cuban women were in the labor force. In 1980 the percent of Cuban women in the labor force increased to 54.9 percent. This trend continued in 1990, with 56.2 percent of Cuban women in the labor force, slightly lower than the percent of women for the U.S total population, which according to U.S census reports increased to 57 percent in 1990 . The figures in Table 3 indicate that Cuban women are still very likely to be employed. 


\section{Table 3}

Number and percent of Cuban women by labor force and employment status

\begin{tabular}{rrrrrrr}
\hline & $\mathbf{1 9 7 0}$ & \multicolumn{1980}{c}{$\mathbf{1 9 9 0}$} \\
\hline Total & 227800 & 100.0 & 379460 & 100.0 & 482250 & 100.0 \\
Employed & 104100 & 45.7 & 193960 & 51.1 & 250644 & 52.0 \\
Unemployed & 9100 & 4.0 & 14580 & 3.8 & 20258 & 4.2 \\
$\begin{array}{c}\text { Not in labor } \\
\text { force }\end{array}$ & 114600 & 50.3 & 170920 & 45.1 & 211348 & 43.8 \\
\hline
\end{tabular}

Employment rate among women remained very high across time. The number of employed Cuban women increased significantly between 1970 and 1980 and remained consistently high through 1990.

\section{Occupational Diversification}

The temporary downward mobility suffered by most immigrant families forced many Cuban women in the U.S to join the labor force and work in blue-collar jobs. The literature on this point indicates that during the first decades of exile, Cuban women were more likely to be employed in the garment industry.

Figure 1 indicates that there have been significant changes in the occupational patterns of Cuban women since 1970. 


\section{Figure 1}

Occupational patterns for Cuban women 1970-1990

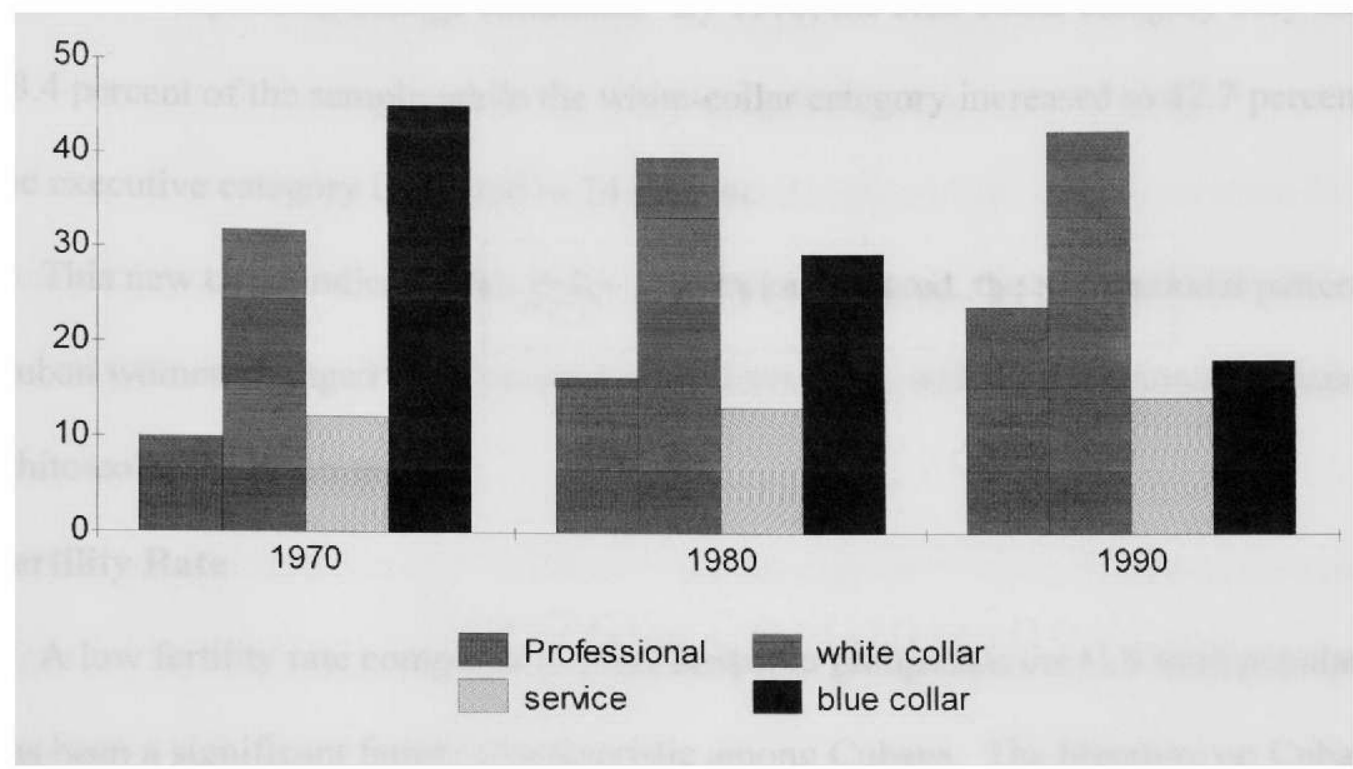

Using census categories, occupations were divided into four groups: 1) Professional occupations which included executive, professional and technical occupations, 2) white collar which included sales and administrative support, 3) service occupations, which included, private household occupations, protective service, an other service occupations, and 4) blue collar, which included precision production and crafts, machine operators and assemblers, transportation and materials moving, helpers, handlers and laborers.

The most significant change in the occupational pattern of Cuban women from 1970 to 1990 was the consistent decrease in the percent of women in the blue -collar category and the also consistent increase in the executive and white-collar categories.

As indicated in figure 1, in 1970, laborers made up 45.3 percent of reported occupations among Cuban women, followed by white-collar occupations with 31.9 
percent. Service occupations accounted for 12.2 of the sample. By 1980 occupational patterns began to change. The percent of women in the blue -collar category decreased to 29.7 , and the percent of women in the white -collar category increased to 40.0 . This trend of occupational change continued. By 1990, the blue-collar category only made 18.4 percent of the sample while the white-collar category increased to 42.7 percent and the executive category increased to 24 percent.

This new trend indicates that as the population matured, the occupational patterns of Cuban women changed: they became more diversified, with a proportional increase in white-collar occupations.

\section{Fertility Rate}

A low fertility rate compared to other Hispanic groups and the U.S total population has been a significant family characteristic among Cubans. The literature on Cuban families indicates that this trend began in Cuba before 1959 and was established in the U.S by the first wave of Cuban immigrants. Cuban women continue to have few children. Using census data on the number of children born to Cuban women between the ages of 15 to 44 , a mean was calculated. Results indicate that the number of children ever born to Cuban women in the U.S between the ages of 15 to 44 has decreased consistently across time, particularly between 1970 and 1980 . The mean of number of children born to Cuban women in 1970 was 1.32 . By 1980 this number decreased to 1.05 , this trend continued and by 1990 it decrease again to 1.04 . 


\section{Summary}

There have been changes in the Cuban family in the U.S. The traditional patterns found in the first migration wave have changed as new trends have emerged, especially between 1970 and 1980 .

As expected, there is a decline in the three-generation household. Higher numbers of elderly are now living on their own. There is a decrease in the number of married couple households and an increase in less traditional family types, especially in female-headed households. The presence of parents and parents in law of the head of household has also decreased.

The level of labor force participation and employment among Cuban women remains high, but there has been a marked shift in the occupational structure. The birth rate remains low.

These new trends in the Cuban household in the U.S are very significant; they illustrate evolution and change, but they do not describe differences among migration waves or the generations, and therefore do not portrait a complete picture. Examining each wave and the second generation across time will provide a more complete view of the Cuban population in the U.S. and will also provide explanations for the observed trends. 


\section{Chapter 5}

\section{Differences among migration waves and the second generation.}

The different migration waves and their distinct character have been a determining factor in the evolution of the Cuban population in the U.S. Each wave contributed to the heterogeneity of the Cuban community. To the first two waves of Cuban migrants, the exiles and the airlift, have been attributed the establishment of cultural patterns that have been crucial in the economic success and social adaptation of Cubans in the U.S. The third wave, the Mariel boatlift, has been considered the most representative of the Cuban population. This wave of immigrants was not perceived as their predecessors. These 1980 immigrants, at least at the beginning, appeared to be different. The Cuban established community feared that the Marielitos would never fully adapt to their new circumstances.

Not only have the different waves been influential in the evolution of the Cuban population in the U.S, the rise of a second generation of Cubans educated in U.S schools and in contact with other norms and values has also influenced this evolution. The second generation of Cubans in the U.S is the product of their parents' circumstances and U.S culture. They are bicultural, bilingual and therefore, different from the first generation. The purpose of this chapter is to identify how differences among the waves, the effects of time, and the birth of a second generation have influenced the Cuban family.

\section{Family types}

Family has been historically one of the most significant social institutions for Cubans in or out of the island, before and after the revolution. By 1959 , the family that had been 
inclusive and extended had already become more nuclear. In the U.S large numbers of Cubans lived in married couple families and their marriages were considered modern and stable (Aguirre, 1981). Lack of resources made the elderly dependent on the family while their economic contribution and their services as caregivers became a significant asset (Perez, 1986). These traditional cultural patterns have been associated with the first two waves of Cuban migrants. It has been assumed that the subsequent waves and the total Cuban population have kept these traditional patterns and social structures.

Figure 2 illustrates that although large numbers of Cubans continue living in married couple households, there has been a decrease in the percent of individuals living in such households, across time and for all three waves.

\section{Figure 2}

Percent of the Cuban-origin population living in married couple households by wave of arrival

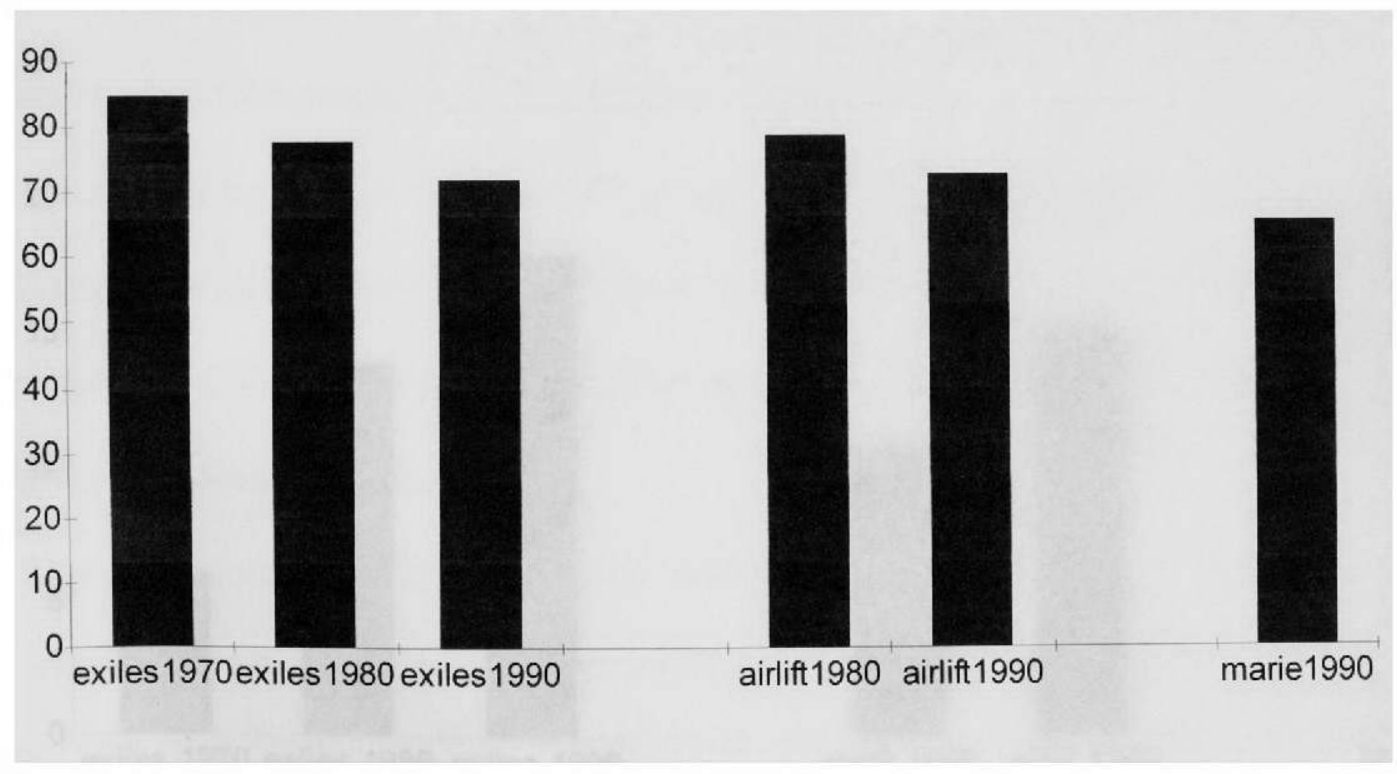




\section{Figure 3}

Percent of Cuban origin population living in female-headed households by wave of arrival

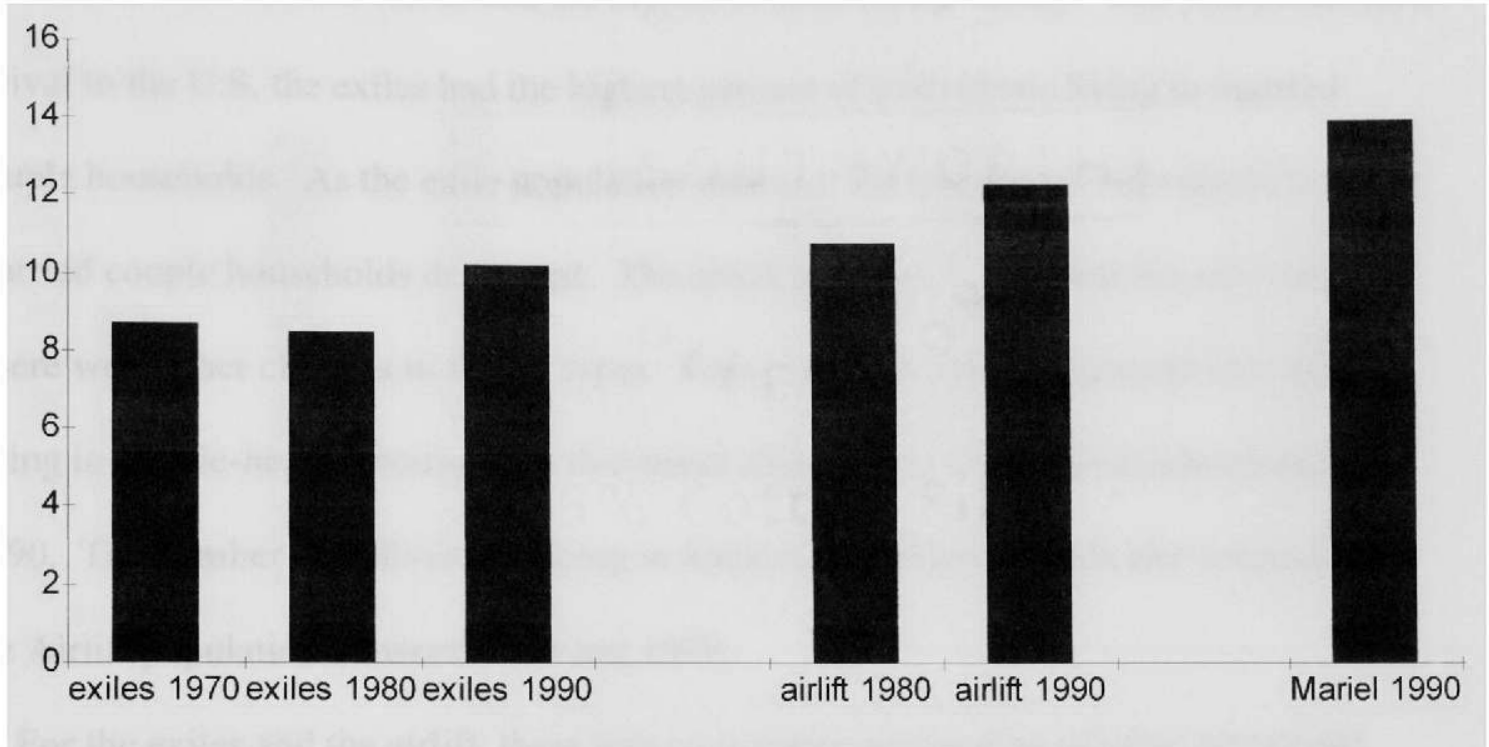

Figure 4

Percent of Cuban origin population living in other types of households by wave of arrival

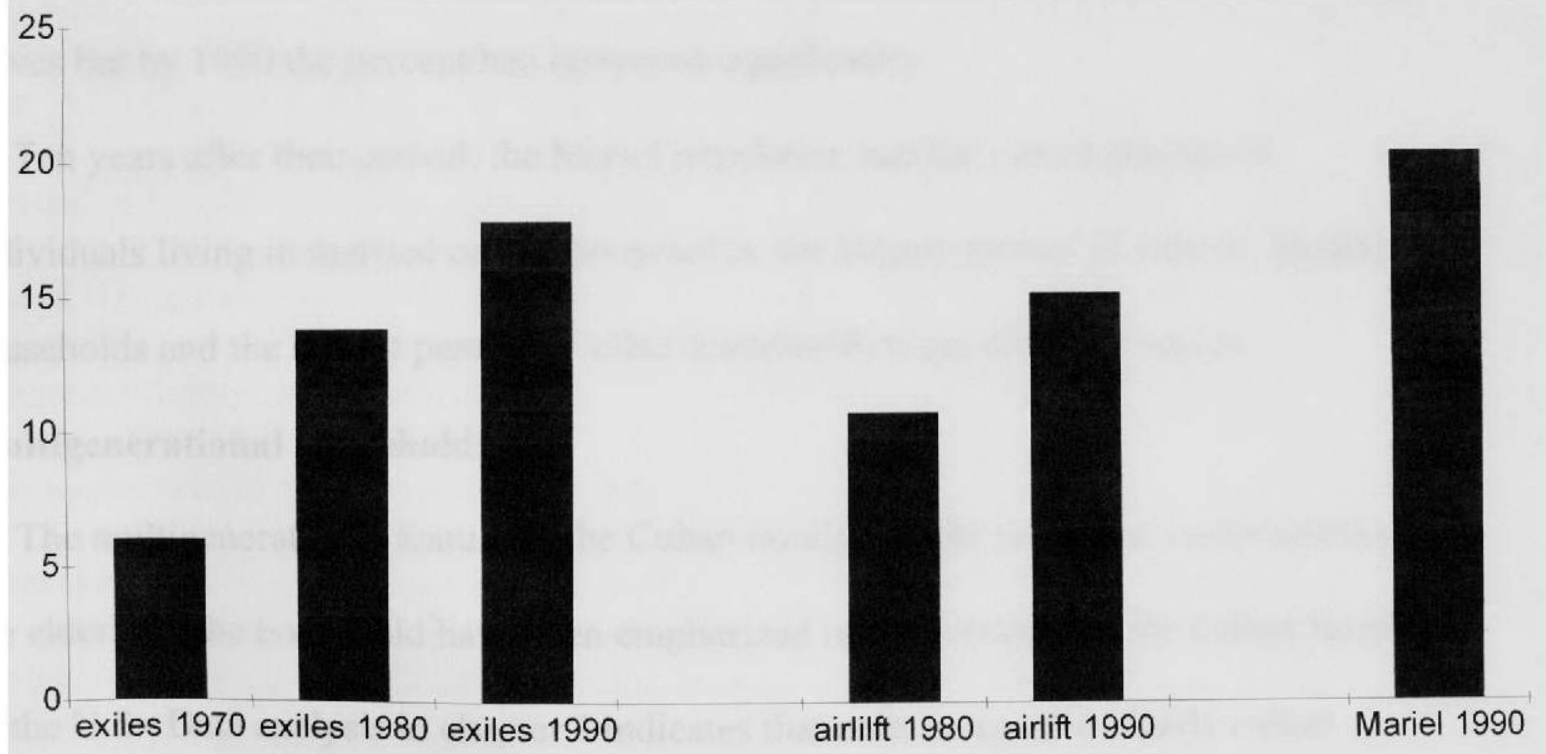


Figures 3 and 4 illustrate that the number of individuals living in other family types have increased with every wave and across time.

Looking at the three waves in ten-year intervals provides a clearer picture of the differences between the waves and the effects of time on the family. Ten years after their arrival to the U.S, the exiles had the highest percent of individuals living in married couple households. As the exile population matured, the number of individuals living in married couple households decreased. The airlift population followed the same pattern. There were other changes in family types. From 1970 to 1980 , the percent of exiles living in female-headed households decreased slightly, but it increased substantially by 1990. The number of individuals living in female-headed households also increased for the Airlift population between 1980 and 1990 .

For the exiles and the airlift, there was an increase across time of other household types, which included individuals living alone or in non-family households. Ten years after their arrival, in 1970 the exiles had the lowest percent of such households of all the waves but by 1990 the percent had increased significantly.

Ten years after their arrival, the Mariel population had the lowest percent of individuals living in married couple households, the largest percent of female- headed households and the largest percent of other households types of all the waves.

\section{Multigenerational households}

The multigenerational feature of the Cuban family and the economic contribution of the elderly to the household have been emphasized in the literature of the Cuban family in the U.S. Data analysis in chapter 3 indicates that each successive elderly cohort became more independent after years of employment and is now living on their own. 


\section{Figure 5}

Percent of individuals over 65 who are heads of households or spouses of heads of households by wave of arrival

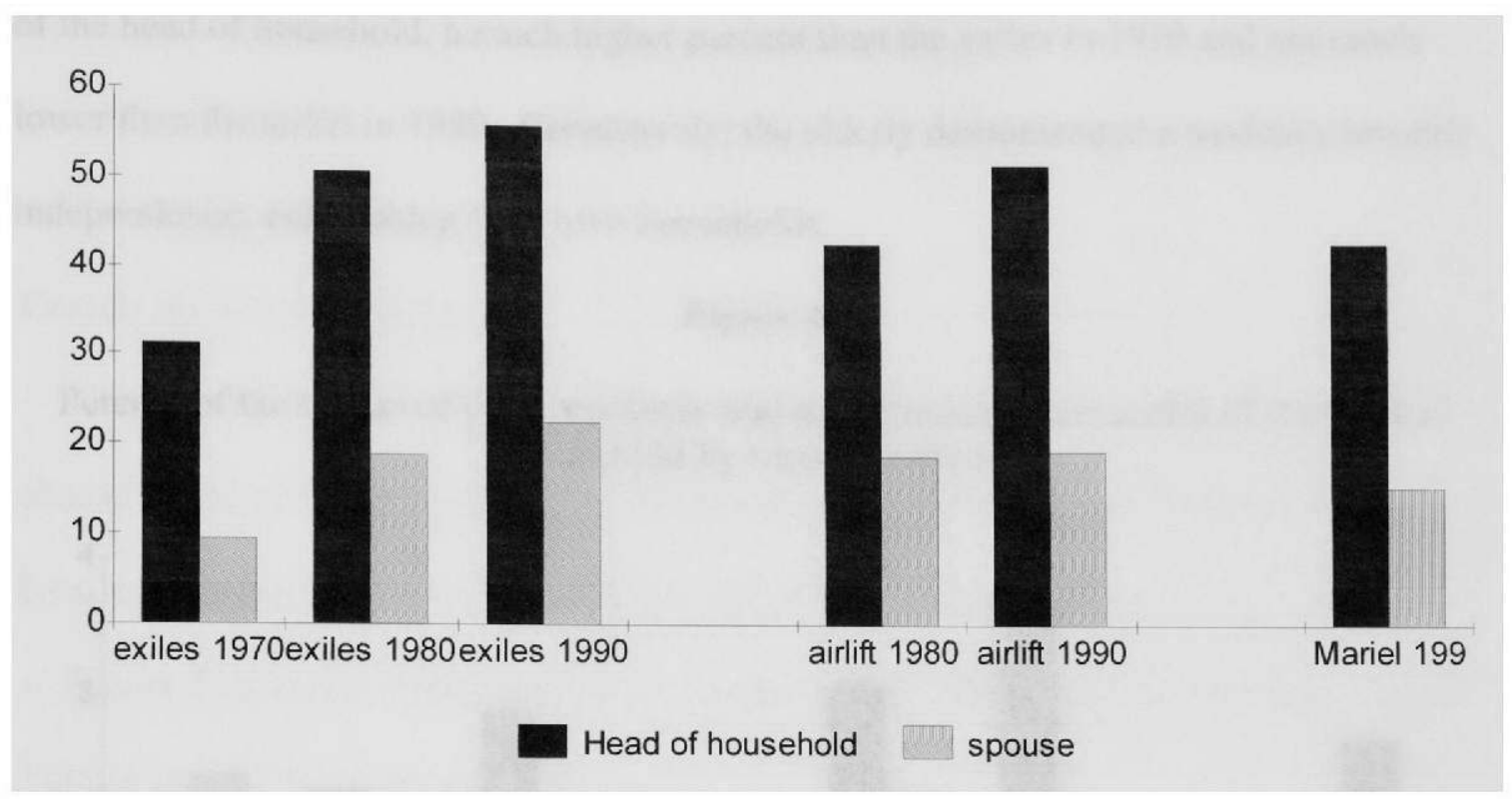

In 1970, ten years after their arrival, only 31.3 percent of individuals 65 and over were heads of household, only 9.4 percent were the spouse of the head of household. By $1980,50.7$ of individuals over 65 were heads of household and 18.9 were the spouse of the head of household. This pattern continued in 1990: 56.4 of individuals over 65 were head of household and 22.6 percent were the spouse of the head of household. The airlift population followed the same pattern. Ten years after their arrival the percent of individuals over 65 who were head of household was higher for the airlift population that it had been for the exiles. In 1980, 43.2 percent of people over 65 were heads of household and 16.1 were the spouse of the head of household. By 1990, the airlift population also presented an increase in the percent of individuals over 65 who were head 
of household, 52.1 percent and 19.5 percent were the spouse of the head of household. For the Mariel population the pattern is not much different. Ten years after their arrival 43 percent of individuals 65 and over were head of household and 15.4 were the spouse of the head of household, a much higher percent than the exiles in 1970 and not much lower than the airlift in 1980. Consistently, the elderly demonstrated a tendency towards independence, establishing their own households.

\section{Figure 6}

Percent of the Cuban origin population who are parents/parents in law of the head of household by wave of arrival

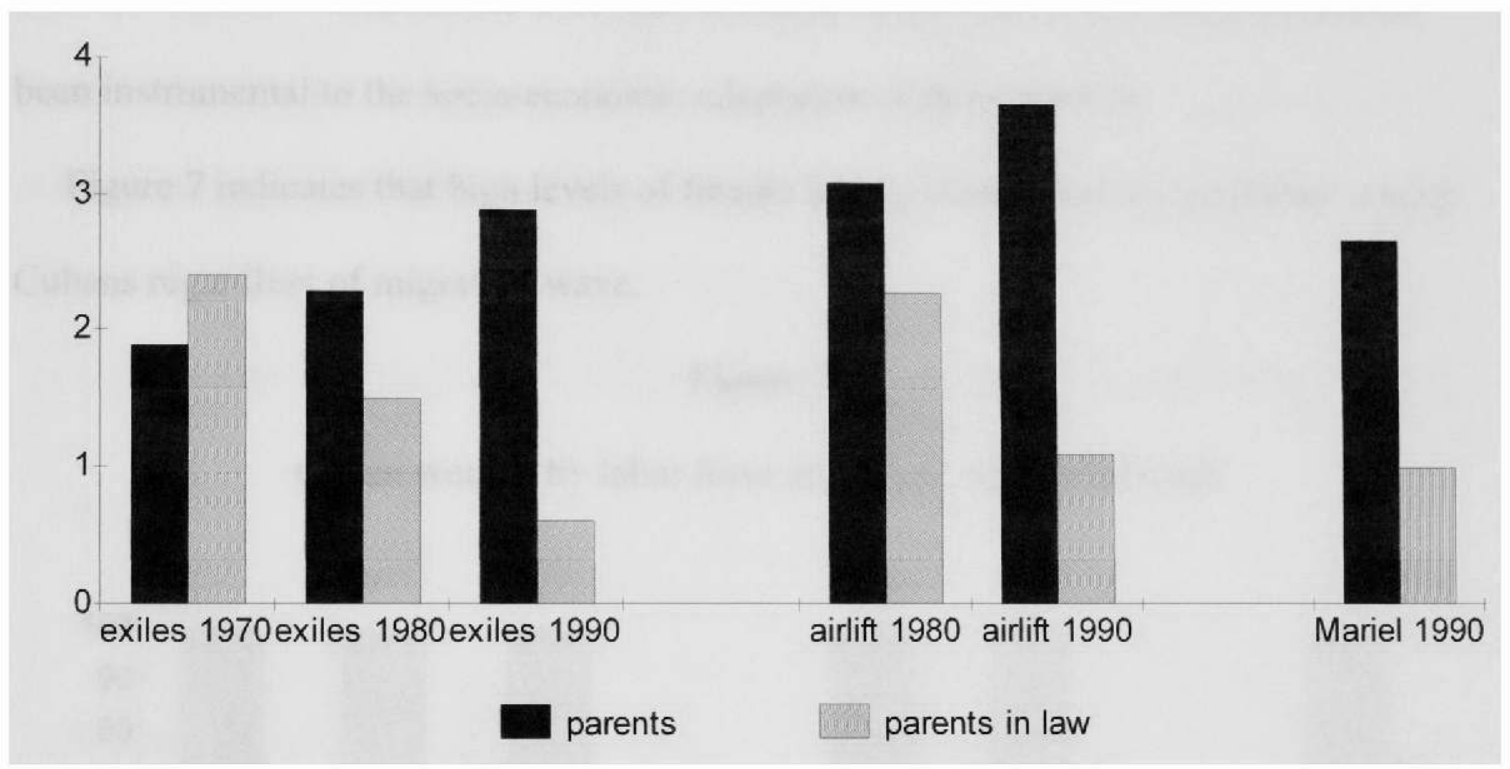

Figure 6 indicates that the presence of parents of the head of household increased for the exiles and the airlift populations, while the presence of parents in law decreased. These figures are consistent with the decrease in the percent of individuals living in married couple families for the total population and each individual wave. As the 
number of married-couple families diminished, the percent of parents in law in the household also diminished.

The Mariel population was not different, although their starting point was different from both the exiles and the airlift (higher that the exiles, lower that the airlift) the presence of parents and parents in law for the Mariel population ten years after their arrival followed the same pattern.

\section{Female labor participation}

High levels of female labor participation and employment have been another salient characteristic of Cubans in the U.S. The economic contribution of Cuban women has been instrumental to the socio-economic adaptation of their families.

Figure 7 indicates that high levels of female labor participation are a constant among Cubans regardless of migration wave.

\section{Figure 7}

Cuban women by labor force status and wave of arrival.

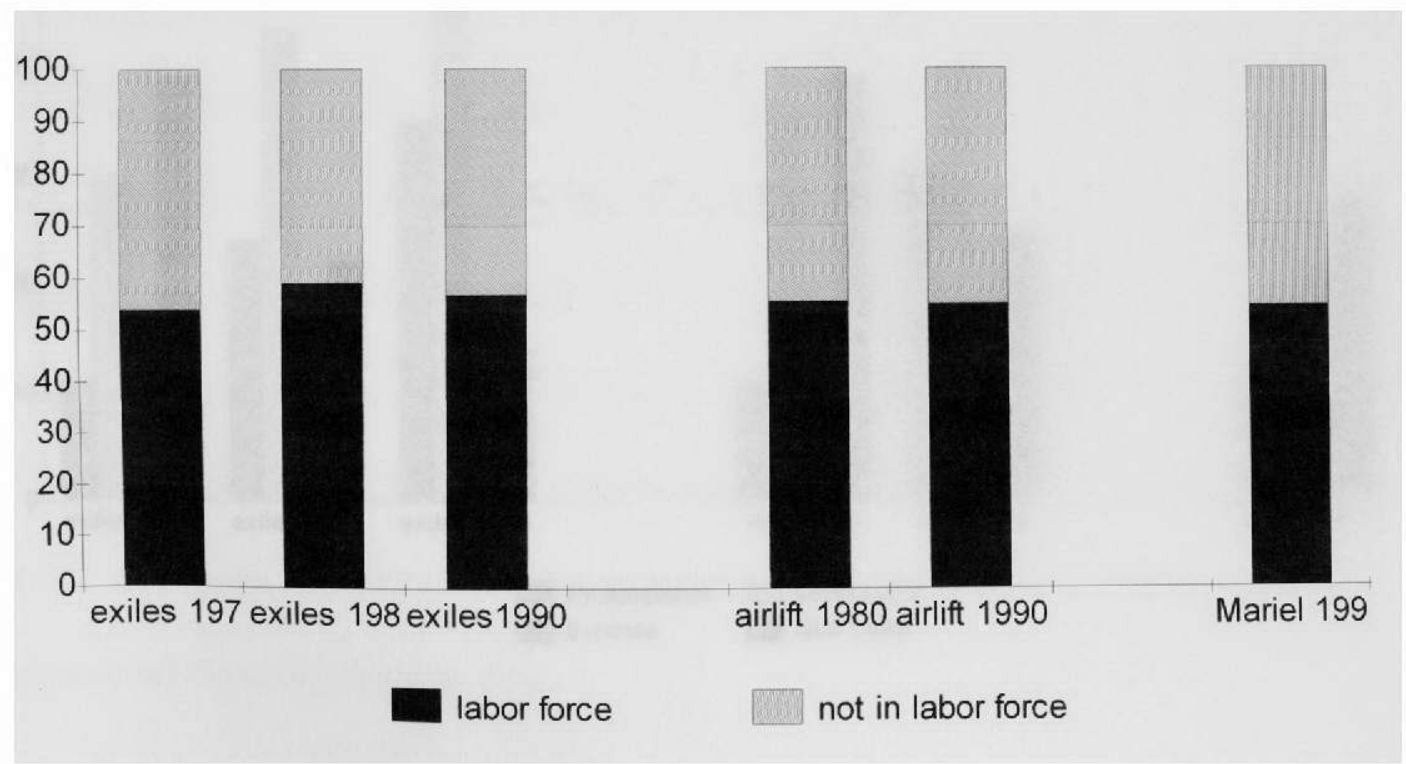


Cuban women continue to have high rates of employment regardless of migration wave. There are however, some differences among the waves. Ten years after their arrival, the exile population had the highest percent of employed women and the Mariel population the lowest. As the exile and airlift population matured the number of employed women increased; by 1990 the percent of employed exile women decreased slightly.

\section{Occupational Diversification}

There have been changes in the occupational patterns of Cuban women from 1970 to 1990. Exile and airlift women were forced to accept blue-collar jobs during the first years in the U.S. In time, occupational patterns changed and by 1990 , Cuban women were no longer mainly laborers instead they were employed in various fields.

\section{Figure 8}

Percent distribution of Cuban women by occupation and wave of arrival

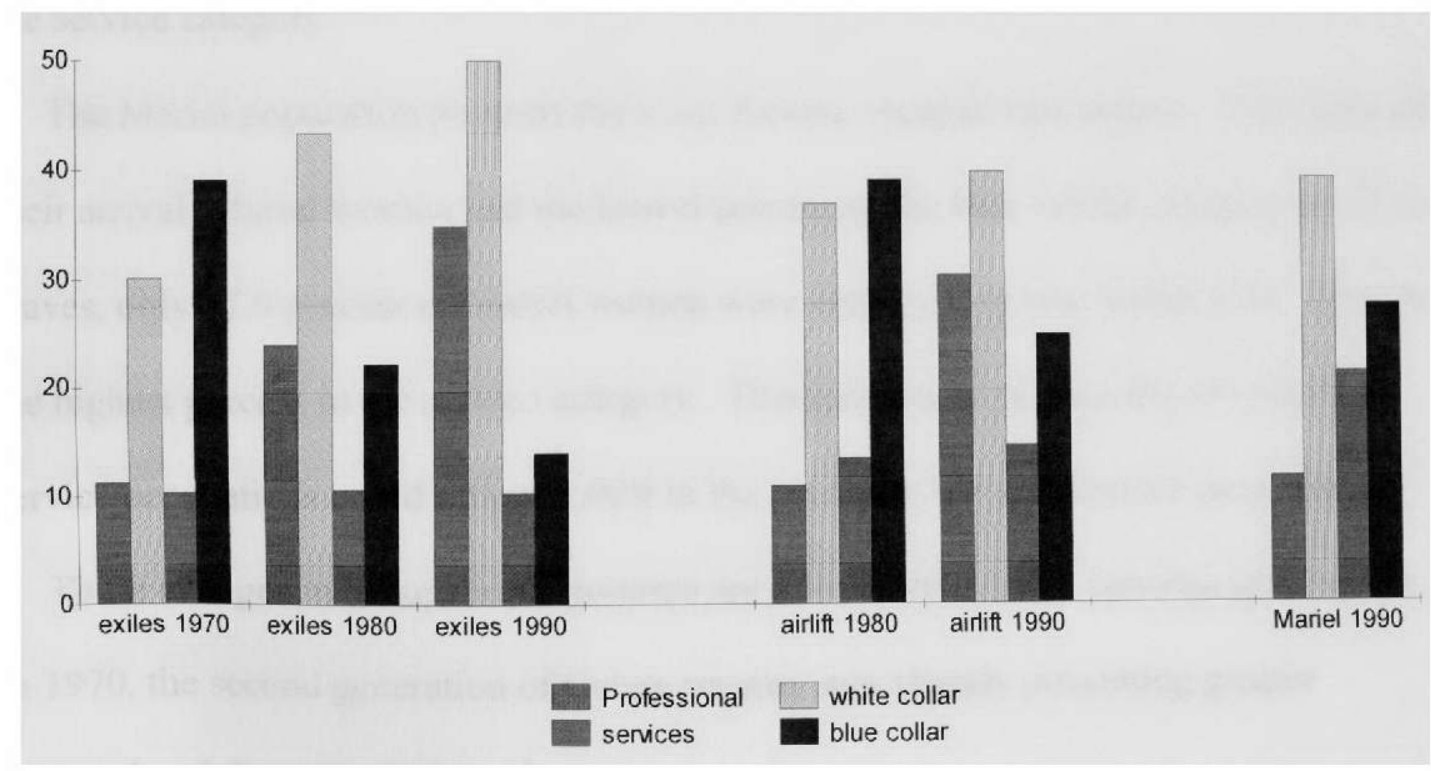


Figure 8 indicates significant changes in occupational patterns for all waves across time. These changes are more evident for the exile population than for the airlift and the Mariel populations. In 1970, 39.1 percent of Cuban exile women were employed in bluecollar jobs; by 1990 only 13.8 percent of exile women occupied such positions. By 1990 exile women were occupied in significant numbers in all four categories but there was a strong inclination for white-collar occupations.

The airlift population presents a similar pattern; an increase in the percent of women in executive and white-collar jobs and a decrease in the percent of women in blue-collar jobs. In 1980, ten years after their arrival to the U.S, 38.8 percent of women from the airlift occupied blue-collar jobs; by 1990 this percent had decreased to 24.6. There was also a clear indication of occupational diversification for the Airlift population, ten years after their arrival, women from the airlift were occupied in all four categories with the same inclination to white-collar occupations and an increase in the percent of women in the service category.

The Mariel population presents the most diverse occupational pattern. Ten years after their arrival, Mariel women had the lowest percent in the blue -collar category of all the waves, only 27.9 percent of Mariel women were employed in blue-collar jobs. They had the highest percent in the service category. This increase in the percent of women in service occupations could reflect a shift in the economy towards service occupations.

These changes in occupational patterns are even more evident between generations. In 1970, the second generation of Cuban women was already presenting greater occupational diversity than the first. 


\section{Figure 9}

Percent distribution of Cuban women by occupation and generation

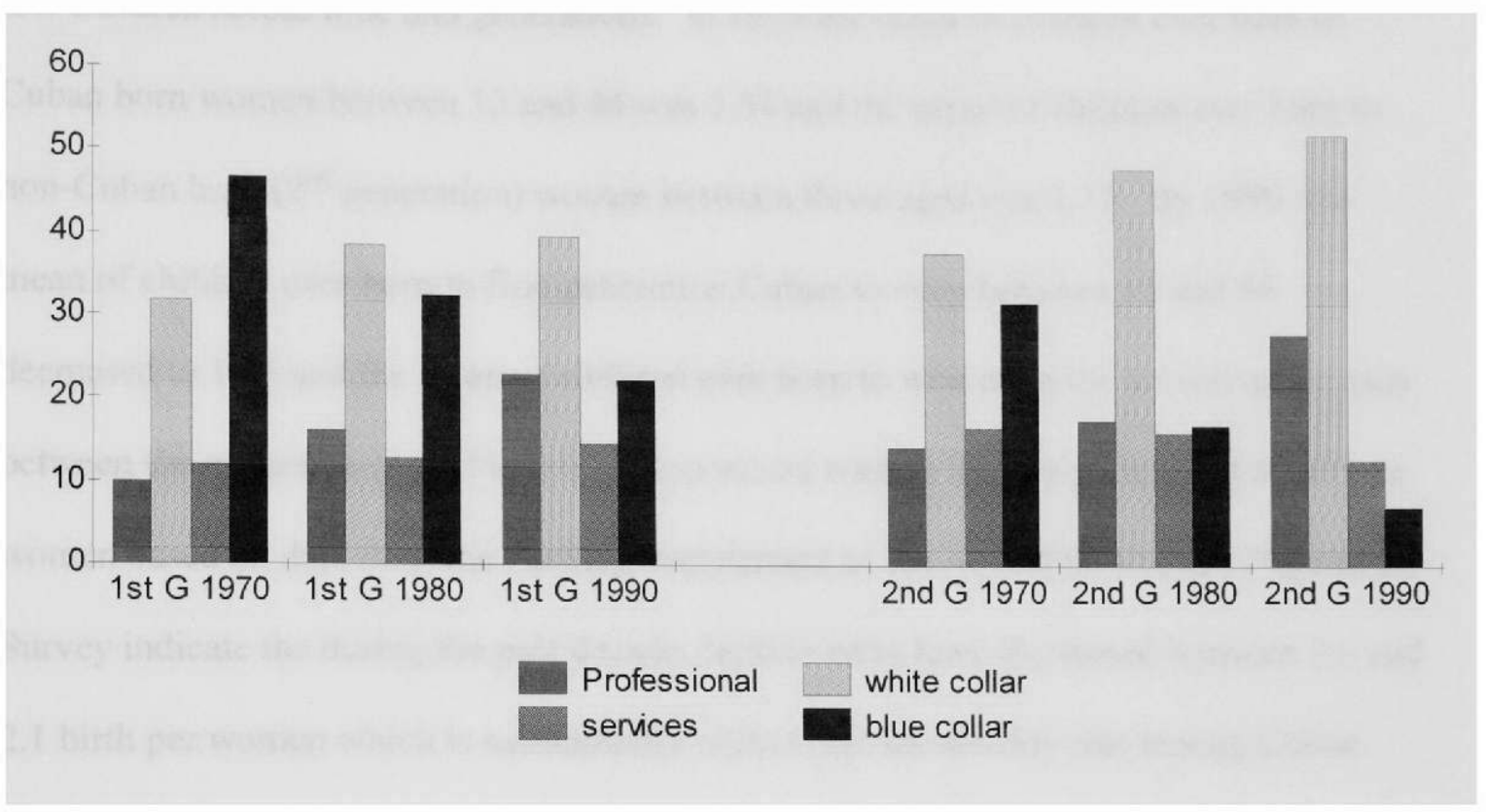

Figure 9 indicates that although both generations present a similar pattern, a decrease on the percent of women in blue-collar jobs and an increase in the executive and whitecollar categories, the first generation presents a more diverse occupational pattern across time. There has been an increase in the number of Cuban born women working in the executive, white collar and service categories. There is a new occupational trend among the second generation, Cuban women in the second generation are occupied in whitecollar jobs more than any other category, there is also a significant increase in the number of women in professional positions, but a slight decrease in the percent of non-Cuban born women in the service category. 


\section{Fertility rate}

Fertility rate among Cuban women has remained low, Cuban women continue having few children across time and generations. In 1970 the mean of children ever born to Cuban born women between 15 and 44 was 1.34 and the mean of children ever born to non-Cuban born $\left(2^{\text {nd }}\right.$ generation $)$ women between those ages was 1.17 . By 1990 , the mean of children ever born to first generation Cuban women between 15 and 44 decreased to 1.28 and the mean of children ever born to women in the second generation between those ages decreased to 0.63 . Reports on current fertility patterns of American women based on data from the Fertility Supplement to the June 2002 Current Population Survey indicate the during the past decade, fertility rates have fluctuated between 2.0 and 2.1 birth per women which is substantially higher than the fertility rate among Cuban women.

\section{Summary}

Time, migration and the birth of a second generation have influenced Cubans in the U.S. The traditional Cuban family has evolved as larger numbers of Cubans live in less traditional households. Larger numbers of individuals live alone, in non-family households, or in female-headed households. The traditional multigenerational household also changed. The presence of parents and parents in law decreased across time for all the waves.

Cuban women present high labor force participation and employment rate regardless of migration wave. However, there are differences among the waves. Ten years after their arrival, the Mariel population had the lowest labor force participation and employment rate of all three waves. There are also clear changes in occupational patterns 
across time. Occupations have become more diverse and new trends have emerged for all three waves and the second generation. Fertility rate continues to decrease across time, especially for the second generation. 


\section{Chapter 6}

\section{Discussion and Conclusions}

As indicated earlier, the intent of this project is to wed two distinct bodies of literature on Cubans in the U.S. One is the literature on the migration process, especially the impact of different waves, their distinctiveness, and the changing contexts of reception on the U.S. This body of work has emphasized the high human capital of the first wave and the enclave it created, an enclave that conditioned the economic adjustment of the later waves and also of the second generation. The second body of literature deals with the Cuban-American family, with an almost exclusive emphasis on the distinctive characteristics of the first wave: the multigenerational household, high female labor force participation, and low fertility. The purpose of the study was to examine the impact of the migration process and generational changes on the family.

As anticipated, there have been changes in the Cuban family in the U.S. The traditional patterns found in the first migration wave have changed across waves and generations. The exposure to a new culture and other values has made less traditional family arrangements socially acceptable among Cubans. Family composition has evolved in the direction of the nuclear family, with a noticeable decline in the threegeneration household. The elderly are now living on their own or in non-family households. Years of employment, eligibility for Social Security benefits and other social programs created by the U.S government at the beginning of the Cold War allowed the elderly to sustain their own households, especially the exiles. Many Cubans still live in married couple households, but increasing numbers have adopted less traditional types, especially female-headed households. Cubans in the U.S., as most migrant groups do, 
keep strong ties to their extended families in and outside the country of origin. Although households have become more nuclear and less traditional, the closeness to the country of origin, the opportunity of traveling between the two countries and the socio economic enclave have preserved strong kin networks.

The level of female labor force participation remains high, but as anticipated, there has been a marked shift in the occupational structure of women, with differences across migration waves and generations. The economic enclave established by the exiles and the airlift population allowed exile and airlift women to venture to different occupational areas. The enclave was particularly influential in the diversification of the occupational patterns of women from the Mariel wave, who by 1990 ten years after their arrival, demonstrated lower percent of participation in blue-collar professions than the exiles and the airlift. The rise of a second generation of bilingual, bicultural individuals educated in the U.S established a new occupational trend. While the occupational patterns of the first generation have become very diverse, the second generation shows a strong inclination for executive and white-collar professions.

The birth rate remains low across migration waves and generations. Fertility rate among Cuban women has been traditionally low and this pattern has been consistent among women from the second generation. Although this is still a very young population, it is anticipated that Cuban women will continue having few children in the U.S.

The evolution of the Cuban family in the U.S is a process that will continue to be influenced by these factors. New immigrants will contribute to further diversify this population. The continuous exposure to U.S culture and to other ethnic groups and the 
relationship to the country of origin will add to this diversification. As the second generation matures and reproduces, the Cuban family in the U.S will experience even more changes.

Although change was anticipated, the extend of some of these changes was not. The most important findings, at the family level and for the total population, are the changes on household composition especially the increase of female-headed households and the decrease of the multigenerational household. Differences among waves were also expected but the most significant finding relates to the Mariel population. The Mariel population who was perceived as very different from the previous waves demonstrated very similar patterns to the Exiles and Airlift. Finally, changes were expected between the first and second generation, the most important intergenerational finding was the new occupational trend among women from the second generation. Cuban women from the second generation have a strong inclination for professional and white-collar occupations.

It would be important for future research on the Cuban family in the U.S to examine the fourth migration wave, the rafters, and compare this population to the previous waves. Future research should also focus on the $2^{\text {nd }}$ generation, especially on women. It should examine the effects of time, migration, and exposure to U.S culture on their perceptions about family and gender roles. 


\section{BIBLIOGRAPHY}

Ackerman, H. \& Clark, J. (1995). The Cuban Balseros: Voyage of Uncertainty. The Policy Center of the Cuban American National Council, Inc. Miami, Florida.

Aguirre, B.E. (1981). The Marital Stability of Cubans in the United States. Ethnicity, 8, 4g, Dec, 387-405.

Ferree, M.M. (1979). Employment without Liberation: Cuban women in the United States. Social Science Quarterly, 60, 35-50.

Garcia, M.C. (1996). Havana USA. Cuban Exiles and Cuban Americans in South Florida, 1959-1994. University of California Press Berkeley and Los Angeles, California.

Grenier, G.J. \& Perez, L. (2003) The Legacy of Exile. Cubans in the United States. Pearson Education, Inc.

Jensen, L. (2001). The Demographic Diversity of Immigrants and Their Children. In Rumbaut, R.G. \& Alejandro Portes. Ethnicities. Children of Immigrants in America. University of California Press.

Foner, N. (1999). The Immigrant Family: Cultural Legacies and Cultural Changes. In Hirschman. C, Kasinitz, P. \& DeWind, J. The Handbook of International Migration. The American Experience. Russell Sage Foundation. New York.

Marina, D.R. (1978). A Theoretical Discussion of What Changes and What Stays the Same in Cuban Immigrant Families. In Szapocznik, J. \& Herrera, M.C. Cuban Americans: Acculturation, Adjustment \& The family. National Coalition of Hispanic Mental Health and Human Services Organization. Washington.

Pessar, P. R. (1999). The Role of Gender, Households, and Social Networks in the Migration Process: A Review and Appraisal. In Hirschman. C, Kasinitz, P. \& DeWind, J. The Handbook of International Migration. The American Experience. Russell Sage Foundation. New York.

Pedraza, S. (1996). Origins and Destinies: Immigration, Race, and Ethnicity in American History. In Pedraza, S. \& Rumbaut, R.G. Origins and Destinies. Immigration, Race, and Ethnicity in America. Wadsworth Publishing Company.

Pedraza, S. (1996). Cuba's Refugees: Manifold Migrations. In Pedraza, S. \& Rumbaut, R.G. Origins and Destinies. Immigration, Race, and Ethnicity in America. Wadsworth Publishing Company. 
Perez Firmat, G. Life On The Hyphen. The Cuban-American way. University of Texas Press. 1994.

Perez, L. (1986). Immigrant Economic Adjustment and Family Organization: The Cuban Success Story Reexamined. International Migration Review, 20, 4-20.

Perez, L. (1986) Cubans in the United States. ANNALS, AAPSS, 487, Sept, 126-137.

Perez, L. (2001). Growing Up in Cuban Miami: Immigration, the Enclave, and New Generations. In Rumbaut, R.G. \& Alejandro Portes. Ethnicities. Children of Immigrants in America. University of California Press.

Rumbaut, R.G. \& Portes, A. (2001). Introduction-Ethnogenesis: Coming of Age in Immigrant America. In Rumbaut, R.G. \& Alejandro Portes. Ethnicities. Children of Immigrants in America. University of California Press.

Smith, L.M \& Padula, A. (1990). The Cuban Family in the 1980's. In Halesbsky S. \& Kirk, J.M. with the assistance of Rafael Hernandez. Transformation and Struggle. Cuba faces the 1990's. Praeger. New York.

Szapocznik, J. \& Hernandez, R. (1988). The Cuban American Family. In Mindel, C., Habenstein, R. \& Wright, R. Jr., Ethnic Families in America: Patterns and Variations. 160-171. New York: Elsevier.

Szapocznik, J., Scopetta, M.A., \& Tillman, W. (1978). In Szapocznik, J. \& Herrera, M.C. Cuban Americans: Acculturation, Adjustment \& The family. National Coalition of Hispanic Mental Health and Human Services Organization. Washington.

U.S Census Bureau. (2003). Employment Status: 2000. Census 2000 Brief (C2KBR-18). Clark SL and Weismantle: Authors.

U.S Census Bureau (2003). Fertility of American Women: June 2002. Population Characteristics (P20-548). Downs, B: Author. 